\title{
Assessment of Oral Health and Hygiene Practices among Students of High School, Hooghly District, West Bengal
}

\author{
Nidhi Shree ${ }^{1}$, Aparajita Dasgupta ${ }^{2}$, Bobby Paul $^{3}$, Lina Bandyopadhyay ${ }^{4}$, Neelam Maurya ${ }^{5}$, Foulisa Pyrbot ${ }^{6}$, Soumit Roy $^{7}$
}

\begin{abstract}
Context: Oral health is a key indicator of overall health, well-being, and quality of life of an individual. India has an alarming population with oro-dental problems. Dental caries and poor oral hygiene constitute more than $50 \%$ of major public oral-health problem, among children and adolescents.

Aim: Aim was to assess the status of oral health and oral hygiene practices among high school students of Hooghly district and find out the factors associated with bad oral health.

Settings and design: Institution-based observational study with cross-sectional design was conducted from July to September 2019 among students of seventh, eighth, and ninth grades of two schools of Hooghly district in West Bengal.

Materials and methods: Using complete enumeration method, out of 288 students enrolled, 194 students were examined. Students filled a self-administered, predesigned, pretested questionnaire following which oral health was examined.

Statistical analysis: Oral health and hygiene practices were separately scored and the bivariate and multivariable analysis was done using SPSS version 16.0.

Results: Half, $86 \%$ of the students had self-reported unsatisfactory oral hygiene practice and $55.6 \%$ students had poor oral health. Males had better oral health and practice scores than females. Female gender 2.22 [1.01-4.89] and Muslim religion 2.55 [1.18-5.53] were significantly associated with bad oral health in the final multivariable model.

Conclusion: Awareness and early start of good oral hygienic practice in childhood can prevent most of the oral diseases. This can pave the way for uptake of timely interventions before any complications set in. Thus, there is a need to inculcate effective Information Education and Communication (IEC) interventions early in childhood to promote good oral health.

Keywords: Adolescent health, Oral health, Oral hygiene practice.

Journal of Oral Health and Community Dentistry (2021): 10.5005/jp-journals-10062-0109
\end{abstract}

\section{INTRODUCTION}

Oral health is one of the key indicators of overall health, wellbeing, and quality of life of an individual. It not only affects people physically and psychologically but also influences how they grow, look, speak, chew, taste food, and socialize in their community. It is sad on our part that dental health has been neglected over the years, especially in the underprivileged areas. Among many reasons, low level of awareness among the population and the care providers, difficulties in availing health care facilities, and so on, has led to continued neglect of dental care. As per the World Health Organization, it is "a state of being free from chronic mouth and facial pain, oral and throat cancer, oral sores, birth defects such as cleft lip and palate, periodontal (gum) disease, tooth decay and tooth loss and other diseases and disorders that limit an individual's capacity in biting, chewing, smiling and psychological well-being".1 Worldwide, $60-90 \%$ of schoolchildren and nearly $100 \%$ of adults have oral problems. ${ }^{2}$ Dental diseases are preventable to a larger extent. However, information and awareness about the preventive aspects of oral and dental health are usually not applied in day-today practice. ${ }^{3}$

In the developing countries like India, dental health is often neglected by majority of population and thus faces increased burden of poor oral health. The burden is largely because of challenges that are less addressed on oral health needs and health care demands. Dental caries and periodontal diseases are a major oral public health problem particularly among the children and adolescents. ${ }^{4,5}$
${ }^{1-6}$ Department of Preventive and Social Medicine, All India Institute of
Hygiene and Public Health, Kolkata, West Bengal, India
${ }^{7}$ Department of Community Medicine, IQ City Medical College,
Durgapur, Burdwan, West Bengal, India
Corresponding Author: Nidhi Shree, Department of Preventive
and Social Medicine, All India Institute of Hygiene and Public
Health, Kolkata, West Bengal, India, Phone: +917439134020, e-mail:
dr.nidhishree23@gmail.com

How to cite this article: Shree N, Dasgupta A, Paul B, et al. Assessment of Oral Health and Hygiene Practices among Students of High School, Hooghly District, West Bengal. J Oral Health Comm Dent 2021;15(3): 108-111.

Source of support: Nil

Conflict of interest: None

In India, till now two large-scale oral health surveys have been conducted, National Oral Health Survey and Fluoride Mapping by Dental Council of India in 2003 and Oral Health in India: Report of multicentric oral health survey by Ministry of Health and Family Welfare in collaboration with Dental Department AlIMS in 2007. These two surveys indicate the prevalence of some oral diseases and conditions in the country. ${ }^{6}$ It was found that overall $40-45 \%$ had dental caries, $90 \%$ had periodontal diseases, $30 \%$ of children had malocclusion, $0.82-3.36$ per 1000 live births had birth defects involving orofacial complex, and so on, and among dental caries 
Table 1: Scoring pattern of oral health and oral hygiene practice among study participants

\begin{tabular}{|c|c|}
\hline \multicolumn{2}{|r|}{ Oral health } \\
\hline Items & 4 items \\
\hline Correct response & $\begin{array}{l}\text { Healthy teeth (1) } \\
\text { Healthy gum (1) } \\
\text { No halitosis (1) } \\
\text { Alignment-good (1) }\end{array}$ \\
\hline $\begin{array}{l}\text { Attainable score } \\
\text { range }\end{array}$ & $0-4$ \\
\hline \multicolumn{2}{|r|}{ Oral hygiene practice } \\
\hline Items & 6 items \\
\hline Correct response & $\begin{array}{l}\text { Use of brush : yes (1) } \\
\text { Use of fluoride-containing toothpaste: yes(1) } \\
\text { Frequency of brushing: }>1 \text { (1) } \\
\text { Frequency of washing mouth } \\
\text { every time (3) } \\
\text { only after major meal (2) } \\
\text { only in morning (1) } \\
\text { Regular consumption of sugary food: No (1) } \\
\text { Visit to a dentist: yes (1) }\end{array}$ \\
\hline $\begin{array}{l}\text { Attainable score } \\
\text { range }\end{array}$ & $0-11$ \\
\hline
\end{tabular}

prevalence, $51.9 \%$ were in 5-year-old children, $53.8 \%$ in 12-year-old children, and $63.1 \%$ in 15 -year-old teenagers. ${ }^{5}$

A study done in 2018 showed that the mean prevalence of dental caries is almost similar at 5 and 12 years at $49 \%$, while it shows steady increase from 15 years (60\%) to $35-44$ years (78\%) and peaks at $65-74$ year group (84\%). ${ }^{7}$ Orodental problems not only cause pain and discomfort to the child but also places a financial burden on the parent. Furthermore, oral diseases restrict activities at school, at work, and at home causing millions of school and work hours to be lost each year throughout the world. It is also seen that exposure to several risk factors which usually starts in adolescence, leads to chronic diseases in adulthood. Thus, prevention of dental problems is considered an important task for the health profession. As schools being an important setting, it offers an efficient and effective way to reach children worldwide and further also their families and community members. Children are particularly receptive during early age. Thus, when earlier the hygienic habits are started, a longer lasting impact can be established. Keeping this knowledge in background, this study was carried to assess the oral health and oral hygiene practice among high school adolescent girls and boys of Hooghly district of West Bengal.

\section{Methods}

A cross-sectional study was conducted for a period of 3 months, that is, from July to September 2019. Based on a study done in 2018 which showed the mean prevalence of dental caries as almost similar at 5 and 12 years as $49 \%,{ }^{7}$ the prevalence of dental caries was take as $49 \%$, taking absolute precision of $20 \%$, type I error as $10 \%$ and nonresponse rate as $20 \%$, minimum sample size came to be 115 . Students of seventh, eighth, and ninth grades were approached after taking proper permission from the principals of the schools for this study. A total of 288 students were enrolled in school in these three classes at the time of study. Out of these, 194 students gave consent for oral health check-up.

Data were collected in two different government high schools, one of which was boy's high school and the other was girl's high school, using complete enumeration method all 194 students were included in the study. Adolescents of seventh, eighth, and ninth grades were included in the study. Students who did not give consent were excluded. They were examined for their oral care, presence of caries, lost or filled or missing tooth, and so on. Data regarding frequency of brushing, changing toothbrush, use of tongue cleaner, mouth wash, and so on were collected by using a predesigned, pretested semi-structured questionnaire. Confidentiality was maintained at every step. Data were entered in Microsoft Excel version 2007 and analyzed using SPSS software 16.0 (SPSS Inc., Chicago, IL, USA). Suitable descriptive statistics were used. Univariate and multivariable logistic regressions were used to determine the factors related with bad oral health. The strength of association was assessed by odds ratio (OR) at 95\% confidence interval; results were considered significant at conventional $p<0.05$ level dependent variable in this study was bad oral health. It had four components, which were assessed by clinical examination-health of the gum, health of teeth, presence of any foul smell (halitosis), and teeth alignment. Independent variables were age, sex, religion, class, education of the mother, occupation of father, type of family, and oral hygiene practice. Scoring pattern of oral health and oral hygiene practice are shown in Table 1.

\section{Results \\ Background Characteristics}

More than one-third, that is, $40.7 \%$ (79) students were from seventh grade and $26.3 \%$ (51) and $33.0 \%$ (64) were from eight and ninth grades, respectively. Participants were in the age-group of 12, 13, and 14 years $26.8 \%$ (52), $27.8 \%$ (54), and $19.6 \%$ (38). Around onefourth, that is, $25.8 \%$ (50) were aged 15 years and above; $57.8 \%$ (112) of students were male, and nearly half of $53.6 \%$ (104) of them were Hindu. More than half $56.7 \%$ (110) belonged to nuclear family. Majority $93.8 \%$ (182) of mothers of the student were homemaker; $29.3 \%$ (57) of mothers were educated till above primary school and $34.5 \%$ (67) of fathers of participants were educated above primary school. One-third, that is, 33\% (64) of fathers were businessmen, rest $67 \%$ (130) were working in either unorganized sectors or as daily wage workers (others).

\section{Behavioral Characteristics}

Nearly two-thirds, that is, $59.7 \%$ (106) students consumed chocolate daily, $45.3 \%$ (88) drank cold drinks frequently, $0.4 \%$ (7) consumed pan masala, and $35 \%$ (68) had cake, biscuits and/or chewing gums daily. Less than one-fifth, that is, $12.8 \%$ (25) had one or more episode of toothache in last 1 month and all having toothache took some treatment either homemade remedy or visited a dentist for medication. And 5.2\% (10) out of 25 were absent for more than 2 days in school because of toothache.

\section{Assessment of Oral Health}

More than half of the participants, that is, $55.7 \%$ (108) had bad oral health and rest $44.3 \%$ (86) had good oral health (Table 2). More than one-third, that is, $42.4 \%$ (86) had unhealthy teeth. And $65.1 \%(56)$ were suffering from caries tooth, $33.7 \%$ (29) had dental plaques, 
$7.2 \%$ (14) had dental erosions, 35.6\% (69) had halitosis, and $38.1 \%$ (74) had unsatisfactory teeth alignment.

\section{Assessment of Oral Hygiene Practice}

Less than half, that is, $42.2 \%$ (82) students brushed their teeth $<2$ times per day. All used brush and toothpaste as teeth cleansing materials. Majority $76.2 \%$ (148) of them practiced rinsing their mouth after having food. Less than one-fourth, that is, $12.8 \%$ (25) used fluoride-containing toothpaste. Majority $62.8 \%$ (122) student never visited dental clinic in last 12 months. Few 13.9\% (27) had satisfactory oral hygiene practice (Table 3).

\section{Bivariate and Multivariable Logistic Regression}

In bivariate analysis among several independent variables, female gender $(\mathrm{OR}=4.45$ [2.37-8.34], $p$ value $=0.001)$, Muslim religion $(\mathrm{OR}=4.95$ [2.65-9.21], $p$ value $=0.001)$, mothers educational level below primary (OR $=1.78[0.95-3.32], p$ value $=0.07$ ), fathers educational level below primary $(O R=2.87$ [1.56-5.29], $p$ value $=0.001)$, and unsatisfactory oral hygiene practice

Table 2: Distribution of study participants according to assessment of oral health $(n=194)$

\begin{tabular}{lc}
\hline Oral health & No. (\%) \\
\hline Unhealthy teeth (multiple response) & $86(42.4)$ \\
(a) Caries tooth & $56(65.1)$ \\
(b) Dental plaques & $29(33.7)$ \\
(c) Dental erosions & $12(13.9)$ \\
Unhealthy gum & $14(7.2)$ \\
Halitosis & $69(35.6)$ \\
Unsatisfactory teeth alignment & $74(38.1)$ \\
\hline Oral health score & \\
\hline Good (4) & $86(44.3)$ \\
Bad (<4) & $108(55.7)$ \\
\hline
\end{tabular}

$(\mathrm{OR}=2.42[1.04-5.59], p$ value $=0.04)$, were found significantly associated with bad oral health. ${ }^{*} p<0.2$ was taken for variables to be significant in bivariate analysis and those were run in final multivariable logistic regression model, where significance was taken for $p<0.05$ (Table 4).

The above five variables were included in the final multivariable model. Adjusted odds of female gender (AOR $=1.85$ [0.83-4.14], $p$ value $=0.132)$ and Muslim religion $(A O R=3.71[1.67-8.21]$ and $p$ value $=0.001$ ) were attenuated but maintained its significance. Adjusted odds of mothers educational level primary and below primary $(\mathrm{OR}=1.78[0.95-3.32], p$ value $=0.07)$, fathers educational level primary and below primary $(\mathrm{OR}=2.87$ [1.565.29], $p$ value $=0.001)$, and unsatisfactory oral hygiene practice $(\mathrm{AOR}=1.82[1.19-2.78], p$ value $=0.005)$ were also attenuated but lost its significance. This model fitting was good as HosmerLemeshow test showed insignificant value and $8.14-24.2 \%$

Table 3: Distribution of study participants according to assessment of oral hygiene practice $(n=194)$

\begin{tabular}{lr}
\hline Oral hygiene & No. (\%) \\
\hline Use of brush & $194(100)$ \\
Use of fluoride-containing toothpaste & $25(12.8)$ \\
Frequency of brushing : >1 & $112(57.7)$ \\
Frequency of washing (rinsing) mouth & \\
(a) Every time after food & $52(26.8)$ \\
(b) Only after major meal & $96(49.5)$ \\
(c) Only in morning & $46(23.7)$ \\
Not regular consumption of sugary food & $37(19.0)$ \\
Visit to a dentist & $72(37.1)$ \\
\hline Oral hygiene practice score & \\
\hline Satisfactory $(>4)$ & $27(13.9)$ \\
unsatisfactory $(\leq 4)$ & $167(86.1)$ \\
\hline Score 4 was the median score attained by the participants
\end{tabular}

Score 4 was the median score attained by the participants

Table 4: Bivariate and multivariable logistic regression showing factors associated with bad oral health $(n=194)$

\begin{tabular}{|c|c|c|c|c|c|}
\hline Characteristics & $\begin{array}{c}\text { Total } \\
\text { number }\end{array}$ & $\begin{array}{c}\text { Bad oral health, } \\
\text { number (\%) }\end{array}$ & $\begin{array}{c}\text { OR } \\
(95 \% \mathrm{Cl}) \\
\end{array}$ & $\begin{array}{c}A O R \\
(95 \% C l) \\
\end{array}$ & $p$ value \\
\hline Gender & & & & & 0.04 \\
\hline Female & 82 & $62(75.6)$ & $4.45[2.37-8.34]$ & $2.22[1.01-4.89]$ & \\
\hline Male & 112 & $46(41.1)$ & 1 & 1 & \\
\hline Religion & & & & & 0.01 \\
\hline Muslim & 90 & $68(75.6)$ & $4.95[2.65-9.21]$ & $2.55[1.18-5.53]$ & \\
\hline Hindu & 104 & $40(38.5)$ & 1 & 1 & \\
\hline Education level of mother & & & & & 0.52 \\
\hline Primary and below primary & 137 & $82(59.9)$ & $1.78[0.95-3.32]$ & $1.29[0.58-2.89]$ & \\
\hline Above primary & 57 & $26(45.6)$ & 1 & 1 & \\
\hline Education level of father & & & & & 0.17 \\
\hline Primary and below primary & 127 & $82(64.6)$ & $2.87[1.56-5.29]$ & $1.70[0.78-3.67]$ & \\
\hline Above primary & 67 & $26(38.8)$ & 1 & 1 & \\
\hline Oral hygiene practice & & & & & 0.35 \\
\hline Unsatisfactory & 167 & $98(58.7)$ & $2.42[1.04-5.59]$ & $1.54[0.62-3.89]$ & \\
\hline Satisfactory & 27 & $10(37.0)$ & 1 & 1 & \\
\hline
\end{tabular}


variability of dependent variable was explained by the model as revealed by Cox and Snell and Nagelkerke $R^{2}$, respectively (Table 4).

\section{Discussion}

In this study, $57.7 \%$ of students brush their teeth twice or more than twice a day. About $12.8 \%$ students use fluoride containing toothpaste. Nearly $62.9 \%$ of students have never visited a dentist. All the subjects rinse their mouth after having food and particularly 49.55\% students rinse their mouth after consuming major meal of the day. Around $50 \%$ participants have self-reported good practice. On evaluation, $86.0 \%$ participants had unsatisfactory practice. A study in the rural area of Tamil Nadu by Vishnu G Ashok and Krishnaprasad $C$ showed that $3.1 \%$ of students brushed twice daily and remaining $46.9 \%$ brushed once daily, $92.5 \%$ were using toothpaste for brushing. About $72.5 \%$ rinsed their mouth always after having food or drink. ${ }^{4} \mathrm{~A}$ study by Bhardwaj et al. found $93.1 \%$ of schoolchildren using toothbrush, and $79.7 \%$ brushing once a day, with $89.8 \%$ using toothpaste. ${ }^{8}$ Dental caries is one of the leading problems in school going children as well as in adults. In the present study, the prevalence of dental caries was noted 56 (65.1\%) more than half of the adolescent students. This is in agreement with the findings observed in studies done by Kulkarni et al. among 11-15 years old children in Belgaum and by Dhar et al. among school going children of rural areas in Udaipur district with a prevalence of dental caries $45.13 \%$ and $46.75 \%$ respectively. Another study by Pratiti et al., in Sundarban, reported the prevalence of dental caries among 13-14 years old schoolchildren to be $72 \%$ which is higher than reported in the present study. ${ }^{4}$ Another study was done at North Jordon by Mahmoud K Al-Omiri. About $83.1 \%$ student used toothbrush and toothpaste, $17.6 \%$ brushed both morning and night. Sixty-nine percent brushed their teeth twice daily. Seventy-five percent of the subjects reported having two or fewer carious teeth. Forty-seven percent reported that they visited the dentist only when they felt pain. ${ }^{9}$ In this study, those who had unsatisfactory teeth, among them $40.3 \%$ students were suffering only from dental caries. In the study at North Jordon by Mahmoud K Al-Omiri, most of the participants were aware that sweets (87\%) and soft drinks (77\%) have a negative impact on dental health. ${ }^{9}$ In the study at Tamil Nadu, 39.4\% had an idea that avoiding sweets and chocolates can prevent tooth decay; in the present study, $43.7 \%$ believe that sweet has a bad effect on teeth, $45 \%$ know that cold drink affects teeth. ${ }^{4}$ In a study at rural area of Tamil Nadu showed that $35.6 \%$ changed their toothbrush in 3-6 months as recommended whereas in present study, $19.2 \%$ of students change their toothbrush within 3 months. ${ }^{4}$ In general, males had better oral health scores than females which were in agreement with some other studies. The strength of the study is that various factors have been considered to find association with oral hygiene practice in detail. Limitation is that it was done in school, so it cannot represent the general population of that age-group. Only the students present on the day on the survey were included in the study, so there are chances of missing some significant findings. The respondents were the children aged 12-15 years, so the socioeconomic status of the family cannot be precisely determined.

\section{Conclusion and Recommendations}

The study showed that bad oral health was strongly associated with gender, religion, education level of parents and oral hygiene practices. Thus, indicating that chance of good oral health increases with the satisfactory practice of oral hygiene. Also it was concluded that males had better oral health practice scores than females.

Thus, early identification of oral health problems in childhood is utmost important as well as preventive and healthy oral behavior adopted in early days of life can become a foundation for a better and disease free positive oral health for future adults. For this purpose proper IEC on oral health has to be stressed upon in school settings from early classes which will inculcate good habit among children and will also pave good foundation for not only oral health but also their overall growth and development.

\section{ACKnOWLedgments}

Researchers acknowledged to the Director of AllHPH, the officer in-charge of UHU and TC Chetla for their kind support and the Department of Preventive and Social Medicine, AllHPH, for the permission to conduct this institution-based research work and also for their technical guidance and help.

\section{References}

1. World Health Organization. Oral Health. 2016. Available from:http:// www.who.int/topics/oral_health/en/. [Accessed March 2, 2020].

2. FDI World Dental Federation. Oral Health Worldwide. 2014. Available from: http://www.worldoralhealthday.com/wpcontent/ uploads/2019/10/FDIWhitePaper_OralHealthWorldwide.pdf [Accessed March 2, 2020].

3. National Oral Health Survey. Dental Council of India. Available from: http://www.dciindia.org.in/Download/Books/NOHSBOOK.Pdf [Accessed November 2, 2019].

4. Pratiti D, Pratyay PD. Prevalence of dental caries among school children in Sundarban, India. Epidemiology 2013:3(4). Available from: http://www.omicsonline.org/prevalence-of-dentalcariesamong-school-children-in-sundarban-india [Accessed November 2, 2019].

5. Bali RK, MathurVB, Talwar PP, et al. National Oral Health Survey \& Fluoride Mapping, 2002-2003, India. Delhi: Dental Council of India; 2004.

6. Operational Guidelines, National Oral Health Program, National Oral Health Cell Directorate General of Health Services Ministry of Health and Family Welfare Government of India 2012:17.

7. Janakiram CS, Antony B, Joseph J, et al. Prevalence of dental caries in India among the WHO index age-groups: A meta-analysis. J Clin Diagn Res 2018,12:08-38. DOI: 10.4103/jpbs.jpbs_239_21.

8. Bhardwaj VK, Sharma KR, Luthra RP, et al. Impact of school-based oral health education program on oral health of 12 and 15 years old schoolchildren. J Educ Health Promot 2013;2:33. DOI: 10.4103/22779531.115820.

9. Kulkarni SS, Deshpande SD. Caries prevalence and treatment needs in 11-15 year old children of Belgaum city. J Indian Sot Pedo Prev Dent. 2002:12-15. Available from: http://medind.nic.in/jao/t02/i1/ jaot02i1p12.pdf [Accessed October 22, 2019]. 